\title{
NIGERIAN YOUTHS IN A GLOBAL WORLD: ACTIVE MUSIC LEARNING AS A PARADIGM
}

\section{Ebele Veronica Ojukwu*\& Young-Sook Onyiuke* http://dx.doi.org/10.4314/og.v15i1.15s}

\begin{abstract}
The young people belong to the largest peer group in history. They live in a rapidly changing world faced with many pressures and challenges and are ill-equipped to tackle their problems. Education is the bedrock of development but in a global world, it is bisected with myriads of problems ranging from poor teaching approaches to paucity of quality teachers and polluted learning environment. The teachers' approaches should be able to prepare learners for challenges of the $21^{\text {st }}$ century. This qualitative study is an attempt to explore the interactive approaches to music education in this era of information technology. This study which is anchored on constructivism theory argues that learning is a process of making meaning and that young people in this global world can develop their existing knowledge and understanding in music education through active interactive approaches to achieve deeper levels of understanding. It concludes by recommending that music teachers at all levels should brace themselves with the life challenges of Nigerian youths to develop in the students, life skills, entrepreneurial thinking and workforce.
\end{abstract}

Keywords: Globalization, Youths, Music education, Entrepreneurship and Active teaching and learning approaches.

\section{Introduction}

There is a general saying that "the world is a global village" meaning that the world is considered a single community linked by telecommunications (Concise Oxford English Dictionary, 2001). Globalization is seen as the process of becoming a more interconnected world. The word "globalization" can be variously defined according to one's sphere of application. It is the process of interaction and integration among people, companies and government worldwide; the process by which businesses or other 
Ogirisi: a new journal of African studies vol. 15s 2019

organizations develop international influence or start operating on an international scale; the word used to describe the growing interdependence of the world's economics, cultures and population brought about by cross-border trade in goods and services, technology and flows of investment, people and information; It is free movement of goods, services and people across the world [https://piie.com]. Carnegie in McKernan (2010) defines globalization as "a process of interaction and integration among people, companies and governments of different nations; a process driven by international trade and investment aided by information technology" [https://hilo.hawaii.edu]. Carnegie further infers that globalization has helped by spreading information technology that can potentially create a sustainable world. No matter the sphere of life, globalization has to do with making something worldwide in scope or application through information technology and other social media.

The emergence of information and communication technology has transformed the world into a global village with the digital revolution and present-day youths want to gain knowledge and develop skills through connecting with and learning from other young people across the world. According to World Economic Forum (2016), "technology has not only shaped the way young people live and work but also created a whole new set of beliefs, fears and aspirations and these values, in turn, will affect their approach to the global challenges and opportunities that lie ahead" [https://www.weforum.org ].

\section{Youths in a Globalized World}

Youth is the period in life between childhood and adulthood, when one can be said to be young. Research has shown that youths constitute three-quarter of Nigerian population ranging from the age bracket of 18 - 35 years and they also constitute a significant and growing percentage of Nigeria. It is also recorded that 43 per cent of the world population are youths. According to Kumar (2013):

This young group is impatient and ready to change the world. Some $70 \%$ of young people believe that social media is a force for change... Around the world, youths are using social media to monitor the effectiveness of public service ... to inform and mobilize their peers. Students are using 
Ojukwu \& Onyiuke: Nigerian Youths in a Global World: Active Music learning...

social media to comment on their schools and inform the public. Most young people are on interactive websites which makes it easy for them to evaluate their schools.

Youths are considered vulnerable in society because of the rapid pace of change they experience in their lives at their adolescence especially in this globalised world. Adolescence age comes with its rapid changes and increased independence which is marked with several physical changes by which their bodies eventually become adult bodies that are capable of reproducing. They are the future wealth of any country since they possess the energy and power and also the embodiment of love and affection. Concerning the feelings of youths, Ojukwu \& Esimone (2014) equivocally asserts, "the feelings of adolescents at a particular period depend on social pressures and society norms which play a big role pressuring how adolescents feel about their body image especially when the changes begin to take place" (p. 164). It is of necessity that the youths of any nation are taking care of in terms of the type of education they receive; the type that will give them the self-confidence, skills and independence they desire; but unfortunately in various countries, it appears they are not appropriately budgeted for in the face of many challenges. Hutt (2016) decries, "technology has not only changed the way youths live and work but also created a whole new set of beliefs, fears and aspirations (and) these values, in turn, will affect their approach to the global challenges and opportunities that lie ahead" [https://www.weforum.org]. Buttressing the above assertion concerning the young people of this age, Ojukwu (2017) emphatically declares, "In the contemporary Nigerian society, many youths are faced with various challenges. The inability of these young people to cope with these challenges result in all-risk behaviour such as lack of confidence, low self-esteem, low motivation, etc" (p.489).

In this globalized world, youths live in a fast-moving terrain characterized as ambitious, enthusiastic, energetic and promising and filled with various challenges. Berger (2017) equivocally maintains that we cannot anticipate the challenges today's children will confront as grownups, nor can we conceive of the solutions they will devise. Technology, the planet, and society are changing faster than ever before and the youths are abreast with these changes. The 
changing of the surrounding world, including the world of music, necessitates a change in music education and teaching and requires that new knowledge and new conditions should be taken into account. Today's youth understand and care more about development than ever before, inspired by the urge to drive meaningful change, peace and prosperity and eager to use their skills to better themselves, their communities and help those in greatest need. Through the transformative power of technologies, young people are putting their talents to use in a field of development to drive real change [https://www.usaid.gov ].

In teaching the young people of this age, the skills that allow them to adapt to rapid change should be an important factor in determining their brighter future; such skills that complement digital technologies should be increasingly in demand. Winthrop (2016) highlights that skill such as communication, teamwork, critical thinking and flexibility, have always been important for work and life, but the current discourse on the youths in this global world makes them even more crucial for the future generation. Education ought to be an integral part of every human being since it moulds one to be a good citizen who is an asset of the country. Young people across the world are advocating and campaigning for education change around the world. Teachers at all levels of education and in all disciplines, including music education, should ensure that youths have the type of education that prepares them to live healthy and productive lives and contribute to their welfare, families, communities and countries.

The task of the music teacher is first and foremost to offer youths the choices of teaching styles that exist in the global world of music; the type that supports them in their personal choices. The method of music learning in numerous Nigerian schools is raising a dilemma in the contemporary period. The problem of how to adapt the music instructions of the older generation into the fast-changing globalised world and educational needs of today's students seems very important. This study portrays active learning strategies as the efficacious means of achieving this.

\section{Theoretical Framework}

Active learning is based on the theory of Constructivism which emphasizes the fact that learners construct or build their 
Ojukwu \& Onyiuke: Nigerian Youths in a Global World: Active Music learning...

understanding. Constructivists argue that learning is a process of making deep meaning out of a given concept. Learners develop their existing knowledge and understanding to achieve deeper levels of understanding. This means that learners are able to analyze, evaluate and synthesize ideas. Skilled teachers make these deeper levels of understanding more possible by providing learning environments, opportunities, interactions, tasks and instruction that foster deep learning.

Active learning is an important component of music education since music education is more practically oriented than theoretical. By engaging music students in the learning process, they are better able to apply the learning they gain to real-life situations. The purpose of this paper is to enhance the role of active learning in music education and to provide strategies for implementing active learning to stimulate higher order thinking and improve music students' motivation to learn musical skills in the globalized world.

\section{Active Learning Strategies}

One of the biggest challenges teachers face in this modern world is to plan lessons that inspire their students to stay actively involved in the learning process. It should be noted that traditional, teachercentred learning plans are no longer conducive to achieving that inspiration. Based on research, it appears that major problem of music education in the modern period is that music education at all levels seems to have shown an inability to answer the challenges posed by fundamental changes in music and culture as well as pedagogy and education in the fast-changing globalized world. Therefore, music education must find a new foundation for its continued relevance and it has to have much common ground with the musical environment of the students.

Learning without meaning is often soon forgotten because without understanding it is difficult to apply information to future reasoning. "Learning is a product of teaching, but it does not always take place just because an instructor teaches" (Bonwell \& Eison, 1991). How teachers understand learning will influence the way they teach and how their student learn as well. Teachers need to transition their concept of learning from simple knowledge acquisition, with leaner's memorizing by rote, towards more consequential knowledge construction with the application of skills. Extending learning to 
Ogirisi: a new journal of African studies vol. 15s 2019 include knowledge and skill applications can require a substantial change in how teachers both understand and approach the teaching and learning

Active learning is any activity that allows students to engage the course material during instruction so that the teacher and the student can ascertain the students' mastery of the materials and adjust the instruction to facilitate further learning (Duquesne University https://www.duq.edu. Active learning methods are an integral part of modern education, including music education. Use of active learning methods helps to develop a person who is active, energetic, and able to collaborate and thinks creatively while being empathetic, respectful towards others and willing to collaborate in both small and large groups (Brown, 2008). Researches have been carried out in various countries on the best strategies to employ in teaching young people to promote active learning. Dewey (1915) recognizes the importance of experiential learning in the classroom. Dewey's submissions maintain that the teacher and the textbook are no longer the only instructors; the hands, the eyes, the ears, in fact, the whole body, become sources of information, while the teacher and textbook become respectively the starter and the tester. No textbook is a substitute for personal experience; they cannot take the place of the actual journey. Kumar (2014) stipulates that the best method to capture the minds, evoke the interest, and enhance the motivation of bored, lost, unchallenged, or unmotivated students is to employ active learning strategies in the classroom.

How knowledge is presented is extremely important for facilitating its acquisition. Using active learning methods enables the teacher to present the subject matter in a way that is more interesting and more easily absorbed by the learner (Aher \& Kala in Jurima; Kivestu \& Steinbach, 2016). In addition to acquiring new knowledge, the use of active learning methods helps to increase students' interest in the subject as a whole. Active learning strategies can be used to empower, engage, and stimulate a classroom by putting students at the centre of the learning process. Discussing the need to embrace active learning strategies in music education in a globalized world, (Berger 2017) states:

These skills prepare students to continue learning throughout their lives. Our economy and society are changing fast..., the 
Ojukwu \& Onyiuke: Nigerian Youths in a Global World: Active Music learning...

jobs of the future mostly don't exist yet..., and so the people who are most likely to thrive are the ones who are prepared to continually adapt and grow [https://medium.com].

Active learning occurs in multiple ways with various names but the principle of student involvement with ongoing feedback remains constant. The principle behind active learning remains consistent with whichever name one chooses, the emphasis should be involving students actively in learning materials while creating a process of offering formative feedback. There are various active learning strategies as there are various educationists of various disciplines and some educationists share similar names while some use different names for the same active learning strategy as can be seen below. Felder \& Brent (1996) identify some active learning strategies to include: substituting active learning experiences for lectures, assigning open-ended problems and problems requiring critical or creative thinking that cannot be solved by following text examples, involving students in simulations and role-plays, assigning a variety of unconventional writing exercises and using self-paced/ or cooperative (team-based) learning. It can also be in the form of using concept test as an informal way of assessing students' understanding. Kumar (2014) suggests the following strategies: Think-pair-share and collaborative learning in which Kumar suggested that learners should work in pairs, discuss materials while role-playing, debate and engage in the case study, Gleason, Peeters, Resman-Targoff \& Denetclaw (2011) stipulate the following strategies: think-pair-share, minute writes, muddiest point, notes exchange, Socratic questioning, debates, fishbowl, role plays, student presentations, games, polling devices/audience response systems (ARS)/clickers, case studies and online supplementation. Going further, Raudys (2018) proffers eight active learning strategies and techniques thus: reciprocal questioning, three-step interviews, the pause procedure, the muddiest point, devil's advocate, peer teaching activities, game-based learning platforms and rotating chair group discussions. These strategies could apply to any discipline including music education. Some of the above-mentioned strategies will be discussed below as it pertains to the teaching of music. 


\section{Reciprocal Questioning}

In this strategy, the music teacher uses reciprocal questioning to encourage an open dialogue in which students take on the role of the teacher and create their questions about given course content in music. It could be music theory, music history, the music of other world cultures, music technology, African music, etc. This is applicable after the teacher had covered a topic of his/her choice in class or after assigning a reading content. This experiential learning activity is a type of student-generated questions. It can be in the form of dividing the class into pairs or small groups and have students come up with a few questions for discussion with the rest of the class. The music teacher can facilitate the process by providing the students with "question stems," which forms a foundation for a question but still require students to think critically about a lesson, text, or other section of material by completing the query. The music teacher could ask the students to use the provided question stems to anchor and explore concepts in the course material, helping students investigate a range of new topics and points of view associated with his/her lesson. Reciprocal questioning involves students in the learning process to help build their comprehension of course material. Reciprocal questioning can be particularly useful when:

- Preparing for tests or exams

- Introducing a new topic or section of course content

- Discussing reading or writing materials in greater detail

\section{Three-Step Interviews}

The three-step interview is a cooperative learning strategy which encourages students to develop active listening skills by quizzing one another, sharing their thoughts, and taking notes. To use the three-step interview process in a music class, the music teacher divides the students into groups of three and assigns three roles: interviewer, interviewee, and note taker. After assigning a theme or topic of discussion, the teacher allows the students to participate in a five to ten minutes' interview to discuss what they found to be the key information relating to the topic. After each interview, the students will be allowed to rotate roles. Depending on factors including the grade level of the students and their experience with 
Ojukwu \& Onyiuke: Nigerian Youths in a Global World: Active Music learning...

the strategy, the teacher may adjust the length of the time for each interview. In three-steps interview: Student interview a partner then, share with team-mates what they learn. The steps involved are as follows:

- The teacher provides the interview topic and states the duration of the interview

- The teacher calls for think time

- In pairs, student 'A' interviews student 'B'

- Pairs switch roles - student ' $B$ ' interviews student ' $A$ '

- Pairs pair to form a group of four.

- Round Robin: Each student, in turn, shares with the team what he/she learned in the interview

\section{The Pause Procedure}

The music teacher can use the pause procedure to intersperse strategic pauses into his/her class lectures and enhance student understanding of teaching materials. To use the pause procedure effectively, the music teacher should arrange for pauses of two to three minutes between every 10 to 15 minutes of lecture time. During these brief breaks, the students should be encouraged to discuss or rework their notes in pairs to clarify key points covered, raise questions, and solve problems posed by the instructor. Alternatively, students can work together to write a paragraph that connects or highlights key ideas set out in their partner's notes. Studies have shown that breaking a lecture into brief pauses can increase student attention and learning outcomes. The study presents pause procedure as a good active learning strategy which helps students review their notes, reflect on them, discuss and explain the key ideas with their partners. The use of the pause procedure involves a minimal amount of extra time but can confer significant benefits in comparison to lectures that continue without breaks.

\section{The Muddiest Point Technique}

The muddiest point technique involves asking students to write notes on the most unclear or most confusing element of a given homework assignment, lecture, or class discussion. The music teacher in the tonal harmony class for instance, using muddiest point technique can ask the following questions: "What have you found to be the muddiest point so far in this tonal harmony assignment? What topic 
Ogirisi: a new journal of African studies vol. 15s 2019

do you find to be the least clear?" Asking students to write down what they find to be the least clear is a powerful exercise because it compels them to grade or rate their knowledge of a topic. The exercise helps students reflect on the topics so far studied and the activity can serve as an insightful source of feedback because, if more than a quarter of the class mentions the same "muddiest point," the teacher may wish to schedule a further time to discuss that topic or create a new lesson plan or assignment to tackle it.

\section{The Debate Approach}

In the debate approach, the music teacher asks one or more students to take the opposing side of a predominant argument or point of view being discussed during a lesson. Once the music teacher has completed an assignment or lesson plan, a topic that is suitable for discussion and debate should be selected. The topic should serve as an appropriate subject for providing arguments from both sides. The activity should be flexible and should be tailored to suit the students' academic level. In its simplest form, the class should be divided into two sections and the teacher should coordinate a class-wide debate based on a selected topic. Alternatively, the teacher may have students annotate reading texts and respond to contentions by creating counter-arguments. Then, he/she may have students debate the proposals discussed during a quiz.

This approach can help cultivate active learning in the music classroom by encouraging students to think more critically, challenging participants to expand their understanding of the perspectives surrounding an issue and to view it through a different lens; become more engaged, fostering involvement by drawing out opinions to explore the complexity of an issue being studied; and produce a deeper understanding of topics or issues, using the rigorous analysis to collectively clarify, probe, and pose alternatives to problems being discussed. The debate approach can help students become more familiar with a topic and its multifaceted viewpoints. A classroom using this strategy can provide students with multiple perspectives, and challenge students with tough questions. In such a classroom, students will become more engaged and students' critical thinking and writing skills will be enriched." 
Ojukwu \& Onyiuke: Nigerian Youths in a Global World: Active Music learning...

\section{Peer Teaching Activities}

The peer teaching approach is flexible and multi-faceted in active learning. Peer teaching compasses a range of scenarios where students instruct skills or explain concepts to classmates. Peer teaching activities help boost vital skills and behaviours including student interaction, accountability, group processing. The music teacher can use any of the following peer group strategies to support his/her teaching especially in keyboard studies and individual performance studies:

- Reading mates: A cooperative learning strategy that pairs two students who work together to read an assigned text.

- Cross-age peer tutoring: A peer learning strategy involving students in different grades, wherein which one student instructs another on the material in which the first student is advanced and the second student is a novice.

- Roleplay: A group of students is split into smaller groups and given a specific task to complete, like in small group work. However, in addition to working on a specific task, the members of each group are asked to play a certain "role". Unlike in traditional role-play, all members of one group play the same role, not individually assigned roles.

\section{Game-Based Learning Platforms}

Game-based learning platforms add depth and differentiation to the educational process and allow students to work with their instructors to achieve their learning objectives. It is about how students use devices to create artefacts of learning that demonstrate conceptual mastery through relevant application and evaluation. This is applicable when students are given challenging problems to solve that have more than one right answer and they are allowed to use technology to show that they understand the concept. This is a very good active learning strategy in music education especially in the area of music composition and music technology

\section{Rotating Chair Group Discussions}

Rotating chair group discussions encourage students to actively listen to selected speakers who follow a pattern of guiding class discussion and summarizing previous points. Students lead and 
stimulate class discussion as they rotate roles, repeatedly selecting the following speaker. This process can be repeated across a variety of courses in music especially school music methods and procedures, with the teacher's guidance to stay on track and help control students. The benefits of rotating chair group discussions are not only limited to the speakers. Knowing that they may be called upon to summarize the previous topic, all students are engaged in attentive listening, frequently jotting down notes and ideas to stay on track in the spaces between speaking. Moreover, students are put into a scenario where they learn from their colleagues' ideas, sparking new considerations of material actively and engagingly. This strategy is rewarding for students because it encourages powerful and direct engagement with course material. To use this strategy effectively, the music teacher should ensure that students adhere to the following pattern:

- When a student wishes to participate, they must raise their hand;

- The student who is speaking calls on the next speaker, ideally someone who has not yet contributed;

- The student who has been called upon briefly summarizes what the previous student said before developing the idea further (The above excerpts were mostly derived from Raudys 2018).

While active learning places an emphasis on the student's role in the learning experience, there is no doubt that the success of any active learning strategy starts with the conscientious teacher's thought and planning. Music teachers should seek to integrate active learning into classroom-based courses and practice experiences throughout all professional music program curricula in this globalised world. Queen's University (2013) opines that not all activities of the teacher will suit his/her particular learning outcomes; many can be modified to get students doing the things that the teacher wants them to do in his/her class. Berkeley University of California (2019) further supports the above assertion and highlights that active learning strategies help to initiate learners and faculty into effective ways to help learners engage in activities based on ideas about how people 
Ojukwu \& Onyiuke: Nigerian Youths in a Global World: Active Music learning...

learn. It further states that multiple active learning strategies may be used in each of the active learning designs.

\section{Surmounting Impediments to Active Learning Implementation}

Research has consistently shown over the years that active learning is the most effective way to teach students virtually all courses. Above assertion notwithstanding, implementing an active-learning approach often is not easy and may involve overcoming a lot of challenges but with patience and perseverance, the challenges could be surmounted. Some of the challenges and ways of surmounting them are discussed below.

There may be barriers about the time involved with creating active-learning tasks, risks involved with implementing them, and school management culture of not providing the instructional materials needed for active learning. The amount of time required to devise the specific components of active learning may involve preparation time similar to that required for creating a new lecture. Teachers have a hard time implementing active learning strategies; it sometimes makes the teacher appear to have lost class control. Some teachers may lack the confidence to implement active learning or may feel that it is risky to share control of the class session with students. Bonwell \& Eison, (199) advise that one strategy to address these potential barriers is careful planning of the class session, perhaps by creating an agenda or outline that details session goals along with placement and time allotment for active-learning strategies. They suggest that it may be easier to start by implementing active learning on a small scale. The school management culture that is supportive of using active learning and provides incentives for members of the staff to implement active learning is of paramount importance.

Students' lack of interest, unwillingness, or unpreparedness to participate in active learning can equally be a barrier. Traditional lectures, with their one-way transmission of information, require little effort from the student. Active learning is a departure from passive learning, as it requires students to think critically and actively engage in the learning process. Giving students clear expectations and instructions on how to participate in this type of classroom learning experience can be helpful. Students can be held accountable for pre-class preparation by being quizzed or given an 
alternate short in-class assessment. If students are expected to learn basic course concepts through pre-class preparation, such as reading assignments, teachers should not use class time to lecture on these basic concepts but rather should be forthright and help students understand the rationale for implementing active learning. For students who are new to this approach to learning in the classroom, the teacher should ensure that initial participation is fun, for example, through the use of a short, active-learning game. Creating a suitable environment in which students can learn, think, be assessed, and receive feedback is important. Finally, teachers should seek ways to motivate student participation, such as awarding participation points or promoting friendly competition. For example, the group that "wins" the game could receive some sort of prize. Students may resist active learning at first, but giving them a clear understanding of the purpose of these activities and holding them accountable for participation may improve their participation in class and their performance on course evaluations. As a result, students may even prove to be more excited and motivated to learn (Gleason et al, 2011).

Other challenges may include systematic challenges, which may include time, testing and lack of resources; student challenges, which include behaviour and range of cognitive abilities; content challenges which include comfort with the content and making it relevant to students; and teachers challenges which include the risktaking by changing teaching methods, the dearth of ideas, and the fact that active learning simply requires greater effort. In short, an active learning strategy takes more time, requires deep content understanding, and involves more resources from schools and creativity from teachers. Edward (2015) opines that there is a lot of pressure on teachers, in an era of testing and test-based accountability and these pressures affect these highly impactful methods. Edward in Augusta further reacts thus:

Middle school-aged classroom management can be challenging. Their hormone systems are regulating. They're changing. And many people think that the best way to control them is to have them sitting in a desk, but research shows that being engaged in physical activities contributes 
Ojukwu \& Onyiuke: Nigerian Youths in a Global World: Active Music learning...

to better classroom management

[https://coenews.augusta.edu].

Edward (2015) proffers three basic ways for teachers who are eager to conquer these challenges and they include: Teachers need to have perseverance and tenacity to do what it takes to make it happen despite all obstacles; Teachers should make their instruction decisions based on how they impact their students. Their focus should be on what is best for the students, and they should be able to put aside their convenience and preferences; teachers using active learning strategies should be adventurous and willing to experiment. They should collaborate with other staff, adjust their approach and try out new ideas from colleagues. These challenges notwithstanding, the benefits of active learning strategies far outweigh the problems. For students, active learning can result in increased content knowledge, critical thinking, and problem-solving, more positive attitudes towards learning, better communication and interpersonal skills, and increased adaptability.

Youths in the global society need intellectually, socially and physically engaging learning activities. They learn through a variety of approaches and all those approaches have merits. Developing self-directed learning skills involves the integration of both classroom and experiential learning because classroom education is the foundation on which experiential education is built and practical experiences reinforce what is learned in the classroom. Teachers in this dispensation have no choice than to brace up to the challenges of the global world; a world faced with huge social challenges and the young people are the most interconnected generation ever, they continue to grow rapidly and the challenges they face are ever more daunting. They have the power to change the world (Osotimehin, 2012).

\section{Conclusion}

This study is an attempt to cue into this great sense of urgency to adapt to millennial learning preferences which are heightened as educators increasingly struggle to capture the attention of today's students. The paper tried to establish that active-learning opportunity in the didactic setting help to set the groundwork for experiential learning by involving students in their instruction and facilitating 
progression from dependent to independent learning. Preparing music graduates to meet the challenges of the youths in this fastchanging world with the pros and cons of social media requires that students actively integrate knowledge, skills, attitudes, values, and behaviours in music practice. There should be a shift of emphasis from teaching to learning in music education. Active-learning strategies should be incorporated more into existing music curricula through both didactic courses and practical music involvement to help students progressively advance to deeper levels of learning. As barriers to the use of active-learning methods are recognized, they can and should be overcome. Teachers need to be convinced and need administrative support and resources to try it. Music students must be prepared to be self-motivated, lifelong learners who can meet the challenges they will face as musicologists in an everchanging society. In the continually changing environment of music practice, developing independent, competent musicologists who are prepared for continuous professional growth is a paramount responsibility for music educators, especially in this global world.

*Ebele Veronica Ojukwu, Ph. D.

Nnamdi Azikiwe University, Awka, Nigeria

ev.ojukwu@unizik.edu.ng

$\&$

*Young-Sook Onyiuke, Ph. D.

Babcock University,Ilishan-Remo, Nigeria

ysonyiukesu@gmail.com, ysonyiuke@yahoo.com 
Ojukwu \& Onyiuke: Nigerian Youths in a Global World: Active Music learning...

\section{References}

Augusta University College of Education. (2020, May). Four barriers to active learning and three qualities to help teachers overcome those challenges.

https://coenews.augusta.edu/archives/1050

Berger, L. (2017). What do young people need to learn today to be prepared for tomorrow?

https://medium.com/xqamerica/what-do-young-peopleneed-to-learn-today-to-be-prepared-for-tomorrow136670d1cd0e

Berkeley University of California. (2019, June). Berkeley centre for teaching and learning. https://teaching.berkeley.edu/activelearning-strategies

Bonwell, C. C., \& Eison, A. J. (1991). Active learning: creating excitement in the classroom. George Washington University Press.

Brown, J. (2008). Student-centered instruction: involving students in their own education. Music Educators Journal, 94(5), 30 - 35.

Pearsall, J. (Ed.), (2001). Concise oxford English dictionary $\left(10^{\text {th }}\right.$ ed.). Oxford University Press

Dewey, J. (1915). Schools of tomorrow. E. P. Dutton.

Duquesne University. (2019. April). Active learning. https://duq.edu/about/centers-and-institutes/center-forteaching-excellence/teaching-and-learning-atduquesne/active-learning

Edwards, S. (2015). Active learning in the middle grades. Middle Grades Research Journal, 9(1) 26 - 32.

Felder, R. M., \& Brent, R. (1996). Navigating the bumpy road to student centered instruction. College Teaching, 442(2), 43-47.

Gleason, B. L., Peeters, M. J., Resman-Targoff B. H., Karr, S., McBane, S., Kelly, K., Thomas, T., \& Denetclaw, T. H. (2011). An active-learning strategies primer for achieving ability-based educational outcomes. American Journal of Pharmaceutical Education, 75(9),

https://www.ncbi.nlm.nih.gov/pmc/articles/PMC3230347/

Hutt, R. (2016). World economic forum: What the young people value. https:////www.weforum.org. 
Ogirisi: a new journal of African studies vol. 15s 2019

Jurima, R., Kivestu, T., \& Steinbach, K. (2016). Possibilities of using active learning methods in secondary schools' music lessons. Future Academy: Cognitive Counseling Research and Conference Services sciences, 5, https://www.futureacademy.org.uk/files/images/upload/32_Ccrcs V5.pdf.

Kumar, R. (2013). Social media and social change: How young people are tapping into technology. https://www.huffpost.com/entry/social-media-and-youngpeople b 2638102

Kumar, S. (2014). Impact of active learning strategies to enhance student performance. Innovare Journal of Education, 2(1), https://innovareacademics.in/journals/index.php/ijoe/article/vie w/891

McKernan, S. (2010). The globalized world. https://hilo.hawaii.edu.

Ojukwu, E. V., \& Esimone, C. C. (2014). Inculcating morals in adolescents through the Igbo folk music. The 2014 WEI International Academic Conference Proceedings New Orleans, USA, 162-171. https://www.westeastinstitute.com/wpcontent/uploads/2014/11/Ojukwu-and-Esimone.pdf

Ojukwu, E. V. (2017). Music education: A vehicle for fostering positive youth Development. UJAH UNIZIK Journal of Arts and Humanities (Special ed.). 489 - 506.

Osotimehin, B. (2012). Young people have the power to change the world.

https://www.theatlantic.com/international/archive/2012/11/you

ng-people-have-the-power-to-change-the-world/265200/

Peterson Institute for International Economics. (2018, October).

Globalization. https://www.piie.com/research/economicissues/globalization

Queen's University (2013). Active learning classrooms. https://www.queensu.ca/activelearningspaces/activelearning/active-learning-queens-playbook.

Raudys, J. (2018). 8 Active learning strategies and examples. https://www.prodigygame.com/blog/active-learning-strategiesexamples/.

Winthrop, R. ((2016). Rethinking education in a changing world. https://www.brookings.edu. 